\section{Achieving Shaker Flask- Scale Cell Densities in Miniprep-Scale Cultures with Baffled Culture Tubes and Growth Medium H15}

BioTechniques 29:1207-1209 (December 2000)

Luria-Bertani (LB) or similar nutrient broths have been the most commonly used media for the routine growth of small-scale $(1-5 \mathrm{~mL})$ bacterial cultures for the preparation of plasmid DNA (1). In an effort to maximize cell densities and, thus, the yield of plasmid DNA, some laboratories have used "rich" media including Terriffic Broth and SOC broth $(4,5)$. More recently, medium $\mathrm{H} 15$ was reported to be among the most efficient of these rich media because the inclusion of biological buffers (MOPS and Tris) makes it possible for cells to undergo biphasic growth (2). The first phase of growth is driven primarily by the use of glucose, while the second phase utilizes casamino acids and yeast extract as the primary carbon and energy sources.

A significant obstacle to the adoption of $\mathrm{H} 15$ medium has been the difficulty of using it for small-scale overnight cultures common in molecular biology laboratories. The superior performance of $\mathrm{H} 15$ medium requires bacterial cultures $(20 \mathrm{~mL})$ to be grown in larger $(300 \mathrm{~mL})$ baffled flasks for maximal aeration (2). In the absence of adequate aeration, fermentation produces a rapid drop in $\mathrm{pH}$ to below 6.0, which causes the cells to enter stationary phase rather than undergo biphasic growth (3). However, when scaled down to 2-mL $E$. coli cultures in standard $15-\mathrm{mL}(100 \times$ $16 \mathrm{~mm}$ ) culture tubes, $\mathrm{H} 15$ reproducibly failed to support the high cell densities achieved with baffled flasks. It was hypothesized that this resulted from a lack of adequate aeration combined with the vicissitudes associated with the preparation of the H15 broth. To circumvent these problems, we have developed a "baffled test tube" that provides for greater aeration, and we have optimized the conditions for the preparation and use of H15 with 2-mL bacterial cul- tures. These modifications make it possible to obtain the same high yields of cells and plasmid DNA that are achieved in baffled flasks.

Bacterial cultures. E. coli strain DH5 $\alpha$ containing plasmid pGEM $^{\circledR}{ }_{-}$(Promega, Madison, WI, USA) was used in the current study. Cultures were inoculated with $50 \mu \mathrm{L}$ of a liquid LB culture of $E$. coli at mid $\log$ phase $\left(\mathrm{A}_{600}=\right.$ $0.6)$ and were incubated at $37^{\circ} \mathrm{C}$ with constant shaking (350 rpm) for $16 \mathrm{~h}$. Spectrophotometric readings $\left(\mathrm{A}_{600}\right)$ were taken at 10,12,14, and $16 \mathrm{~h}$. All cultures had reached stationary phase by $16 \mathrm{~h}$ post-inoculation, and no significant increases in cell densities were seen at 20 or $36 \mathrm{~h}$ post-inoculation. All experiments were performed in triplicate. Because of the extremely high cell densities supported by H15, a standard curve relating cell density to optical absorbance at $600 \mathrm{~nm}$ was generated by serial dilution of a 16-h liquid culture (Figure 1). The relationship between $\mathrm{A}_{600}$ values and cell density is described by the $\log$ equation $[y=1.77+$ $1.08 \log (\mathrm{x})]$. All comparisons of cell density were calculated by interpolation of this line. The coefficient of determination for this line $\left(r^{2}=0.992\right)$ is virtually indistinguishable from the idealized value of 1.0 for this statistic. This made it possible to accurately compare cell densities across a broad range of optical absorbance values.

H15 medium preparation. Table 1 shows the composition of H15 medium, which was prepared in $100-\mathrm{mL}$ aliquots. The RNA (ICN Biomedicals, Costa Mesa, CA, USA), yeast extract, casamino acids, and RNase A were added to $80 \mathrm{~mL}$ sterile water and stirred until dissolved (15-30 min). MOPS and Tris were then added simultaneously to avoid extremes in $\mathrm{pH}$. The conditions under which $\mathrm{H} 15$ is prepared and stored impact the performance of the medium. First, the addition of glucose before autoclaving, or its addition to hot $\mathrm{H} 15$ after autoclaving, results in the formation of unstable products accompanied by a precipitate, which completely inhibits $E$. coli growth (2). However, even when glucose is added to cool $\mathrm{H} 15$ and stored at $4{ }^{\circ} \mathrm{C}$, a precipitate forms within a week with concomitant inhibition of cell growth. To ameliorate this problem, glucose-free 
H15 medium can be prepared and stored $\left(-20^{\circ} \mathrm{C}\right)$ to which sterile glucose is added immediately before use. Even when prepared without glucose, how ever, the performance of autoclaved H15 medium was often inconsistent. Optimal and reproducible performance was only achieved by sterilization of H15 through a $0.45-\mu \mathrm{m}$ pore size filter (Millipore, Bedford, MA, USA).

Baffled culture tubes. In the original report on $\mathrm{H} 15$, bacteria were cultivated in $20 \mathrm{~mL}$ media in baffled 300 $\mathrm{mL}$ flasks for maximal aeration (2). A search of glassware suppliers, however, failed to turn up baffled culture tubes that would allow for maximal aeration of 2-mL liquid cultures more commonly used in molecular biology laboratories. We therefore modified standard $(100 \times 16 \mathrm{~mm})$ glass culture tubes (Fisher Scientific, Pittsburgh, PA, USA) to create a baffled tube. This was done by heating the base of the tube with a Bunsen burner until the glass had softened. The sharp corner of a razor blade was then rapidly pressed into the wall of the tube producing a triangular indentation approximately $15 \mathrm{~mm}$ above the base of the tube (Figure 2).

To assess the efficacy of the baffled tubes, bacteria cultivated in LB and H15 broth in standard (smooth wall) tubes were compared to identical cultures
Table 1. Composition of H15 Growth Medium

\begin{tabular}{|lc|}
\hline Component & Concentration \\
\hline Torula Yeast RNA & $1 \% \mathrm{w} / \mathrm{v}$ \\
Yeast Extract & $5 \% \mathrm{w} / \mathrm{v}$ \\
Casamino Acids & $1 \% \mathrm{w} / \mathrm{v}$ \\
Glucose & $2 \% \mathrm{w} / \mathrm{v}$ \\
MOPS & $250 \mathrm{mM}$ \\
Tris & $289 \mathrm{mM}$ \\
RNase A & $10 \mu \mathrm{g} / \mathrm{mL}$ \\
& \\
(pH medium to 7.6 with $\mathrm{HCl}$ ) \\
\hline
\end{tabular}

grown in baffled tubes. Figure 3 presents the results of these comparisons. The performance of the optimized H15 medium was found to be superior to that of LB medium regardless of the type of culture tube used. In standard culture tubes, cell densities supported by $\mathrm{H} 15$ medium were up to $330 \%$ of the densities recorded for cultures grown in LB medium at matching time points. Similar results were seen with baffled tubes in which cell densities with $\mathrm{H} 15$ were up $380 \%$ of those recorded for corresponding cultures in LB broth. When the results obtained with $\mathrm{H} 15$ in standard tubes were compared to those from baffled tubes, a two-way analysis

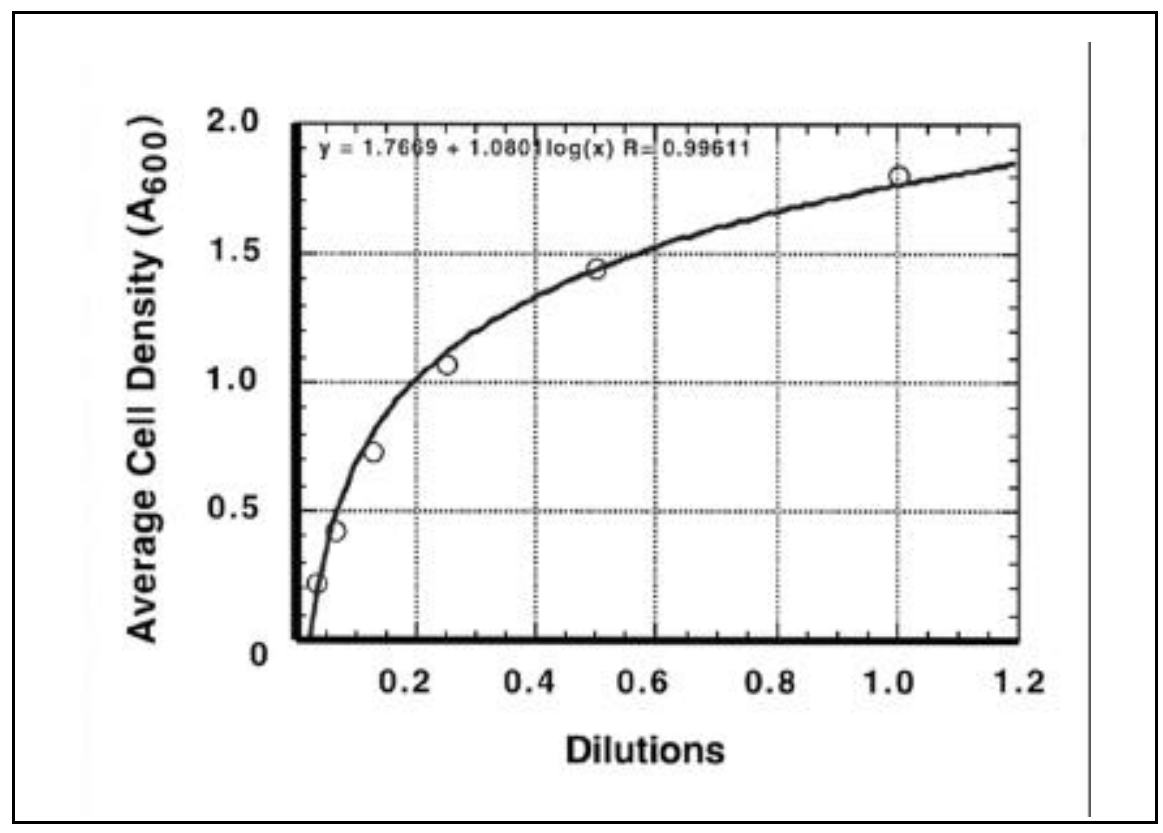

Figure 1. Standard curve of optical density at $600 \mathrm{~nm}$ plotted against serial dilutions of cells from a 16-h culture of $E$. coli grown in $\mathrm{H} 15$ broth in a $15-\mathrm{mL}$ baffled tube shaken at $350 \mathrm{rpm}$. of variance (ANOVA) demonstrated that the use of baffled tubes produced significantly $\left(\mathrm{F}_{\mathrm{s}}: 488.0 ; \mathrm{df}: 1,16 ; P<<\right.$. $0.001)$ greater cell densities. Conversely, the cell density of cultures grown in LB was virtually identical regardless of whether standard or baffled tubes were used. This was not unexpected because LB medium does not include glucose as a carbon source, thereby avoiding the potential for a rapid fermentation-driven drop in $\mathrm{pH}$. Most importantly, the cell density of 2-mL E. coli cultures grown for $16 \mathrm{~h}$ in baffled culture tubes using the optimized $\mathrm{H} 15$ broth $\left(\mathrm{A}_{600}=\right.$ 1.815) was indistinguishable from that of a 20-mL H15 E. coli culture grown in a baffled $300-\mathrm{mL}$ flask as a control $\left(A_{600}=1.810\right)$.

Additional considerations. Beyond modifications to the preparation of the H15 medium and the use of baffled culture tubes, we noted one additional consideration for the use of $\mathrm{H} 15$ in molecular biology laboratories where the use of X-gal in blue/white selection screens is common. Inoculation of H15 medium (which does not contain X-gal) with colonies grown on agar containing ampicillin $(50 \mu \mathrm{g} / \mathrm{mL})$ and X-gal (33 $\mu \mathrm{g} / \mathrm{mL}$ ) resulted in a significantly longer lag phase and lower cell density at 10,12 , and $14 \mathrm{~h}$ post-inoculation than was observed for colonies taken from agar containing ampicillin only (Figure 4). A two-way ANOVA demon-

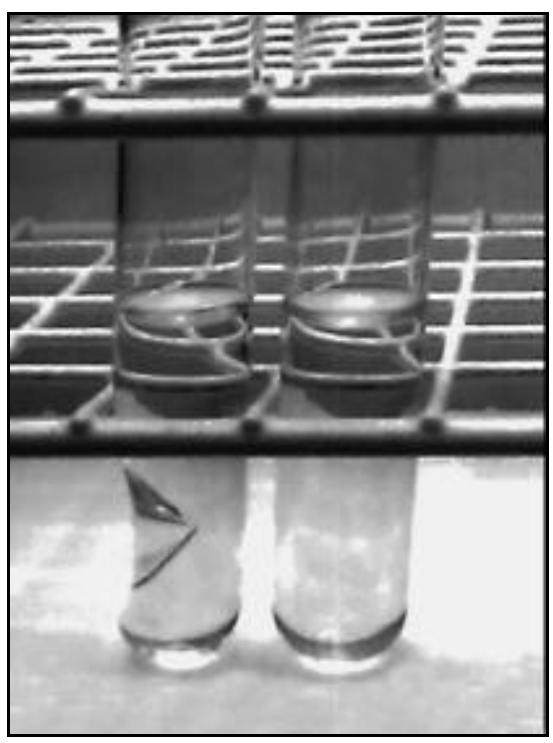

Figure 2. Photograph of a 15-mL baffled tube (left) and 15-mL smooth wall tube (right). 
strated that this difference in the two growth curves was statistically significant $\left(\mathrm{F}_{\mathrm{S}}: 522.6 ; \mathrm{df}: 1,16 ; P<<0.001\right)$. The reason for this phenomenon is unknown, but by $16 \mathrm{~h}$, both cultures had reached nearly equivalent cell densities.

In conclusion, modifications to the preparation of $\mathrm{H} 15$ broth, including the preparation of glucose-free medium and filter sterilization, significantly improve the storage and reliability of $\mathrm{H} 15$ growth medium. Furthermore, the use of baffled glass culture tubes enhances aeration and, thus, the performance of the H15 medium in small-scale bacterial cultures. As measured by optical absorbance, use of H15 broth in 2-mL overnight cultures now supports growth to the same high cell densities (i.e., nearly four times greater than that with
LB media) that previously were only attainable using much larger and more expensive baffled flasks. These modifications offer researchers the opportunity to significantly boost the efficiency and yield of the small-scale bacterial cultures that are used for a wide variety of applications including the preparation of plasmid DNA and the heterologous expression of proteins.

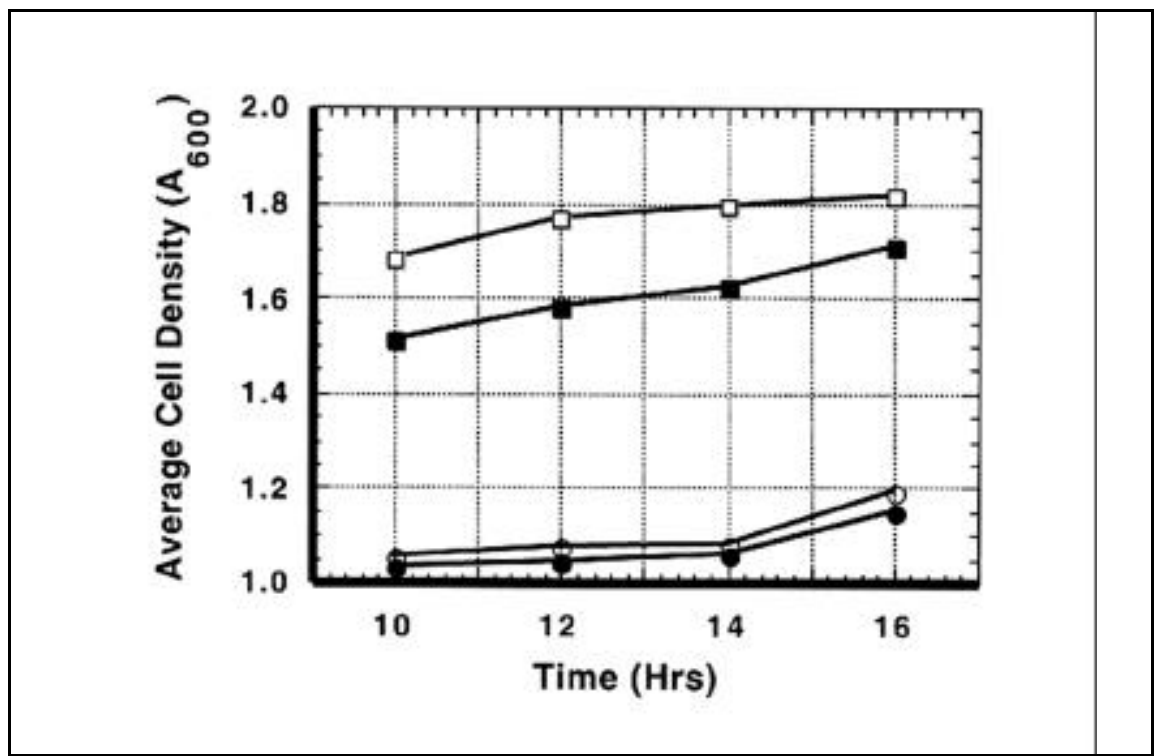

Figure 3. Graph of cell densities, based on optical absorbance $(600 \mathrm{~nm})$, of 2-mL cultures of $E$. coli measured at 10, 12, 14, and $16 \mathrm{~h}$ after innoculation of either LB or $\mathrm{H15}$ media in 15-mL standard culture tubes or 15-mL baffled tubes. (•) LB in standard tubes; (O) LB in baffled tubes; (๘) H15 in standard tubes; ( $\square$ () H15 in baffled tubes.

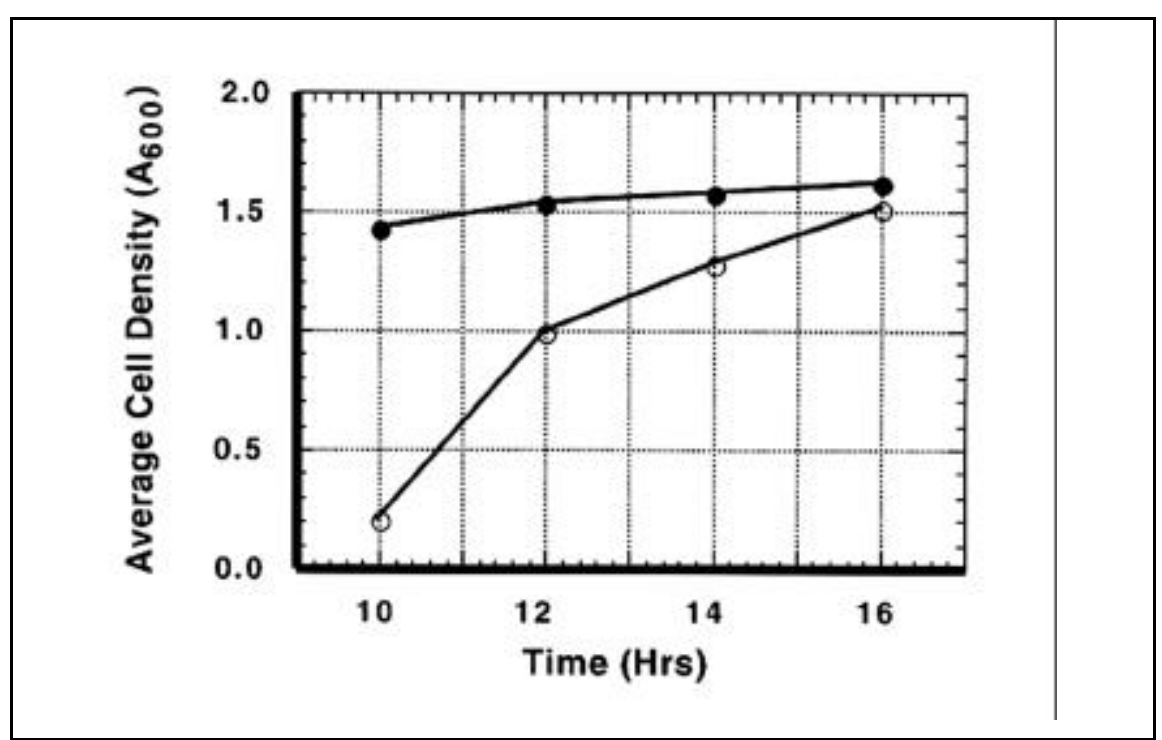

Figure 4. Graph of cell densities based on optical absorbance $(600 \mathrm{~nm})$ measured at $10,12,14$, and $16 \mathrm{~h}$ after innoculation with $E$. coli taken from agar containing: (•) ampicillin only or (o) ampicillin and X-gal into $\mathrm{H} 15$ broth in baffled 15-mL tubes.

\section{REFERENCES}

1.Del Sal, G., G. Manfiolett and C. Schneider. 1989. The CTAB-DNA precipitation method: a common mini-scale preparation of template DNA from phagemids, phages or plasmids suitable for sequencing. BioTechniques 7:514520.

2.Duttweiler, H.M. and D.S. Gross. 1998. Bacterial growth medium that significantly increases the yield of recombinant plasmid. BioTechniques 24:438-444.

3.Luli, G.W. and W.R. Strohl. 1990. Comparison of growth, acetate production and acetate inhibition of Escherichia coli strains in batch and fed-batch fermentations. Appl. Environ. Microbiol. 56:1004-1011.

4.Sambrook, J., E.F. Fritsch, and T. Maniatis. 1989. Molecular Cloning: A Laboratory Manual, 2nd ed. CSH Laboratory Press, Cold Spring Harbor, NY

5.Tartof, K.D. and C.A. Hobbs. 1987. Im proved media for growing plasmid and cosmid clones. Bethesda Res. Lab. Focus 9:1216.

This work was supported by National Science Foundation grant no. IBN-9806888 to J.C.F. and P.B.D. Address correspondence to Dr. Phillip B. Danielson, University of Denver, Department of Biological Sciences, 2190 E. Iliff Avenue, Denver, CO 80210,USA.e-mail:pdaniels@du.edu

Received 27 March 2000; accepted 14 August 2000.

\section{L.J. Vigil, P.B. Danielson, C. Sollars, T.M. Yee and J.C. Fogleman University of Denver Denver, CO, USA}

